\title{
AVANÇO NEOPENTECOSTAL NO FUTEBOL BRASILEIRO: ANÁLISE SÓCIO-ANTROPOLÓGICA ACERCA DAS RELAÇÕES ENTRE RELIGIÃO, FUTEBOL E ESPAÇO PÚBLICO NO BRASIL
}

\author{
The spread of Neo-Pentecostalism in Brazilian football: \\ socio-anthropological analysis of the relationship between religion, football \\ and public space in Brazil
}

\author{
Claude Petrognani ${ }^{1}$ \\ claude.petrognani@libero.it
}

Universidade Federal do Rio Grande do Sul, Porto Alegre, Brasil

Fecha de recepción: 19-VI-2015

Fecha de aceptación: 17-VIII-2015

Resumo: Este texto se mobiliza em torno das relaçôes entre religião, futebol e espaço público no Brasil. Mais especificamente, discorre sobre um aspecto do campo religioso brasileiro: a saber, o campo evangélico, em particular o neopentecostal e a sua inserção e rápida difusão no meio esportivo, principalmente o futebol.

A partir de dados da pesquisa de doutoramento, será possível, sem pretensão exaustiva, demonstrar que há um avanço evangélico, fazendo desta configuração religiosa muito mais que «uma das religióes periféricas ou marginais dos brasileiros» (Carvalho, 1999, p. 3), podendo ser considerada uma religiáo "hegemônica" quase como o catolicismo, no que diz respeito ao ambiente futebolistico.

1 Doutorando em Antropologia Social pelo Programa de Pós- Graduação em Antropologia Social (PPGAS) da Universidade Federal do Rio Grande do Sul (UFRGS), Porto Alegre, Brasil. Bolsista CAPES. Contato: Claude.petrognani@libero.it Endereço profissional: Programa de Pós- Graduação em Antropologia Social (UFRGS) - Av. Bento Gonçalves, 9500 - Prédio 43311, Bloco AI, Sala 104 , CEP 91509-900 -Porto Alegre, RS, Brasil. 
Além disso, tentar-se-á mostrar que o interesse evangélico, no que diz respeito aos esportes, com o grupo denominado Atletas de Cristo, aprofunda as suas raízes na herança da Muscular Christianity de era vitoriana (1837-1901).

Enfim, este objeto permite refletir sobre um tema crucial da atualidade, o fenômeno da religião no espaço público.

Palavras chaves: Religião; futebol; espaço público; neopentecostalismo: Atletas de Cristo; Muscular Christianity.

Авsтract: This text deals with the relationship between religion, football and public space in Brazil. Specifically, it is about a certain aspect of the Brazilian religious field, i.e. the evangelical field, and particularly the Neo-Pentecostal one and its appearance and spread in sports, mainly football. By using data taken from doctoral research, it will be possible to demonstrate, without claiming to be exhaustive, that there is a spread of evangelicalism in football which is making this religious movement grow out of the status of a "peripheral or marginal religion for Brazilians" (Carvalho, 1999, p. 3), and turning it into a "dominant" religion almost as important as Catholicism, with regard to the world of football. Moreover, this text will try to show that, with reference to the group called Athletes of Christ, the interest in evangelicalism in the field of sports is not a recent phenomenon but it traces its origins to the heritage of Muscular Christianity, which dates back to the Victorian Age (1837-1901). Finally, this text aims to stimulate reflection on a fundamental contemporary theme, i.e. the phenomenon of religion in public space.

Keywords: Religion; football; public space; Neo-Pentecostalism; Athletes of Christ; Muscular Christianity.

SUMÁRIO: 1. Introdução: breves consideraçóes sobre religião, futebol e espaço público no Brasil. 2. Alguns números acerca do crescimento neopentecostal no futebol. 3. Religião e esporte: modalidade muscularidade cristã. 4. Os Atletas de Cristo: muscularidade cristã pós-moderna. 5. Consideraçóes finais. 6. Referências bibliográficas.

\section{INTRODUÇÃO: BREVES CONSIDERAÇÕES SOBRE RELIGIÃO, FUTEBOL E ESPAÇO PÚBLICO NO BRASIL}

$\mathrm{O}$ avanço evangélico, mais especificamente neopentecostal, no espaço público brasileiro é um fenômeno incontestável (Sanchis, 1997; Carvalho, 1999; Oro, 2003; Montero, 2006; 2009; Pierucci, 2012).

De fato, a mais "hegemônica» das "religióes periféricas ou marginais», parafraseando Carvalho (1999, p. 3), bem se aproveitou do processo de diferenciação entre as esferas do político e do religioso: laicizando-se, o Brasil, de um ponto de vista religioso, se pluralizava (Pierucci, 2012). 
Resumindo, enquanto o Catolicismo perdia a sua hegemonia (jurídica) retraindo-se do espaço social, outras denominaçóes religiosas entravam na disputa para ampliar a dimensão religiosa do espaço público (Montero, 2006; 2009, Carvalho, 1999).

Casanova (2013) mas também Montero $(2006 ; 2009)$ demonstraram a ineficácia sociológica do paradigma secular e da sua aplicabilidade à realidade brasileira.

De fato, se tomarmos a secularização como conceito analítico, assim como a conceberam os seus teóricos da secularização (In: Cipriani, 1981), torna-se evidentemente impossível esboçar uma analise do quadro contemporâneo da(s) religiosidade(s) no Brasil (Sanchis, 1997; Carvalho, 1999, Montero, 2006; 2009).

Sem entrar em detalhes, no custa lembrar que no Brasil o processo de modernização, ou seja de diferenciação e emancipação das esferas políticas, econômicas e científica em relação à religiosa não produziu, como irreversivel conseqüência, um enfraquecimento da religiáo como força social e a sua invisibilizaçâo (Luckmann, 1967) na esfera pública.

Dito diferentemente, a secularização do Estado no seu ordenamento jurídico (disestablishement) não coincide com a secularização da vida das pessoas (In:Pierucci, 2012).

Muito pelo contrário, as religióes dos brasileiros (In: Sanchis, 1997) estão cada vez mais visiveis, e, longe de se tornar "questóes (exclusivamente) ligadas aos afetos dos coraçôes» (Geertz, 2001, p. 151) partilham, competindo, um espaço público heterogêneo e efervescente (Sanchis, 1997; Carvalho, 1999).

Sintetizando: «secularização no plano jurídico -estatal, vitalidade religiosa no plano sociocultural» (Pierucci, 2012, p. 90).

A título de exemplo, e muito superficialmente, perambulando pelo Mercado Público de Porto Alegre, ponto nevrálgico (e portanto estratégico) da cidade, é possível se deparar com nitidez com expressóes e manifestações religiosas plurais: rituais de batuque, umbanda ou quimbanda, oraçóes de pastores evangélicos e partidos politicos manifestando também as próprias religiosidades seculares (Piette, 1993).

Em outras palavras, o espaço público se configura como um território atento não somente às liberdades de religião mas também da religiāo, corroborando a tese que o fundamento da separação Igreja/Estado (o Estado brasileiro é laico desde a Constituição de 1891) repousa na construção de uma sociedade civil na qual as pessoas de diferentes religióes e crenças podem conviver pacificamente, uma sociedade laica na qual o Estado (idealmente ${ }^{2}$ ) garante as mesma liberdades e direitos a todos.

De acordo com Pierucci (2012, p. 88): «Muito embora essa concorrência (religiosa) seja evidentemente imperfeita, a assimetria dos contendores não impede que todo instante o cenário se 
Assim a laicidade "é um conceito insubstituível " (Baubérot, 2011, p. 59) que não limita as liberdades, mas, pelo contrário, as sustenta e as amplia, como é o caso do Brasil ${ }^{4}$.

O ponto de partida é, portanto, a pluralidade da oferta religiosa ${ }^{5}$ na esfera pública, isto é, como os agentes religiosos não simplesmente se introduziram nas esferas da sociedade civil brasileira (Montero, 2006) mas como contribuíram para a sua constituição sui generis, ou melhor, à brasileira (Mariano, 2011; Oro, 2011).

Aqui, o que nos interessa, é avançar algumas consideraçóes no que diz respeito a um dos componentes em disputa, estou me referindo à chamada virada neopentecostal (Rial, 2013).

Retornamos, por instantes, em Porto Alegre.

Em ocasiáo do megaevento da Copa do Mundo (2014), me deparei com grupos de jovens que se apinhavam nos principais pontos turísticos da cidade (praça da Alfândega, praça do Mercado) entregando um curioso livrinho (disponível em português e inglês): na capa estava representada uma máo que segurava uma medalha, a qual, por sua volta, estava irradiada de uma luz branco/amarela. Um pouco abaixo, o título do livrinho anunciava: «VENCEDOR: o Evangelho de João com testemunhos de grandes atletas» e estava emoldurado num provável gramado de futebol.

A imagem descrita sintetiza perfeitamente o conúbio entre esporte (futebol) e religião, assim como o proselitismo (que não escapou à imprensa internacional) nas praças públicas da cidade, visibiliza as dinâmicas que se interpóem entre religiáo e espaço público.

diferencie e pluralize com o aflorar inestancável de um empreendedorismo religioso inteiramente inesperado".

3 Escreve Baubérot (2011, p. 59): «As laicidades possuem em comum o fato de articular quatros princípios (...) a garantia da liberdade de consciência, a igualdade e a não- descriminação, a separação de político e do religioso, a neutralidade do Estado no que diz respeito às diferentes crenças. O termo laicité é portanto insubstituível».

4 Pierucci (2012, p. 89) também sustenta que: «Em termos históricos empiricos- causais, essa liberdade toda (...) outra coisa não é senão a conclusão lógica (direta e trivial) da separação entre Estado e Igreja operada pela República de 1889 e logo inscrita na Constituição de 1891. Eis, pois, o dado fundamental e fundador:a separação Estado/Igreja. (...) Pessoas livres (re)querem Estado laicos. A operação inaugural e principal da modernidade religiosa é o disestablishment, portal da liberdade de religião. (...) Também no Brasil o disestablishment foi a pedra fundamental e continua sendo a pedra de toque da nossa modernidade religiosa, sua entrada principal».

5 A esse respeito ver Pierucci (2012) e Mariano (2001).

6 De acordo com Montero (2006, p. 59) «O pentecostalismo está no Brasil desde 1910 com a chegada da Congregação Cristá (...) mas foi na década de 1980 que o pentecostalismo ganhou a visibilidade que tem hoje, não apenas em razão de seu crescimento numérico, mas também pela sua presença na esfera pública e nos meios de comunicação». 
Este texto, portanto, se mobiliza em torno das relaçóes entre religião, futebol e espaço público no Brasil. Mais especificamente, discorre sobre um aspecto do campo religioso brasileiro: a saber, o campo evangélico, em particular o neopentecostal e a sua inserção e difusão no meio esportivo, principalmente o futebol.

A partir de dados da pesquisa de doutoramento, será possível, sem pretensóes exaustiva, demonstrar que há um avanço evangélico, fazendo desta configuração religiosa muito mais que "uma das religióes periféricas ou marginais dos brasileiros ${ }^{7}$ " (Carvalho, 1999 , p. 3), podendo ser considerada uma religiäo "hegemônica» quase como o catolicismo, no que diz respeito ao ambiente futebolístico.

Além disso, tentar-se-á mostrar que o interesse evangélico, no que diz respeito dos esportes, com o grupo denominado Atletas de Cristo, aprofunda as suas raízes na herança da Muscular Christianity de era vitoriana (1837-1901).

Enfim, este objeto permite de refletir sobre um tema crucial da atualidade, o fenômeno da religião no espaço público.

\section{ALGUNS NÚMEROS ACERCA DO CRESCIMENTO NEOPENTECOSTAL NO FUTEBOL}

O crescimento numérico do campo evangélico, em particular do pentecostalismo de segunda e terceira ondas (Freston, 1994) ou neopentecostalismo (Mariano, 1995) é incontestável.

Passou-se, nas últimas três décadas (1990-2010), de 14 milhões a 42 milhões de evangélicos ${ }^{8}$, ou seja, houve um crescimento significativo de $200 \%$. Em particular, só o segmento dos pentecostais, hoje, somam acerca de 35 milhóes. Isto significa que, a propósito do campo evangélico, haveria uma relação de quase 3 pentecostais a cada 4 evangélicos.

Se considerarmos que a população brasileira é de acerca 200 milhóes (em 2013) e que a quantidade de católicos, apesar de uma tendência negativa (houve um decres-

7 De acordo com Carvalho (1999, p. 3) o Catolicismo, por razóes históricos - sociais, se configura, até agora, "como a religião hegemônica no país». Contudo, entre as religióes ditas "periféricas ou marginais - as religiôes chamadas em geral de espírita» - vale apontar, desde já, a entrada maciça dos pentecostais, que, como escreve Sanchis (1997,p. 30) «é o fenômeno mais visivel no campo cristão brasileiro (...) náo só na arena religiosa em geral, mas nos seus ponto de alta visibilidade, especialmente populares».

8 Em: Oro, A.P. Universidade de Roma Tre. 14/05/2014 Os dados estão disponíveis em: <http:// www.europa.uniroma3.it/cipriani>.

De acordo com Pierucci (2012, p. 92), adotando na nossa análise os dados dos censos demográficos 1990, 2000, 2010, estamos conscientes «das limitaçôes inerentes ao tipo de informação que um censo demográfico costuma apresentar, como por exemplo a impossibilidade de resposta múltipla à pergunta "qual é a sua religião", o que de cara exclui de registro os sincretismos todos e as duplas filiaçóes». 
cimento de cerca $23 \%$ nas últimas três décadas) se mantém o centro das religióes dos brasileiros, com acerca de 123 milhóes de brasileiros, poder-se-ia dizer que em termos numéricos os evangélicos aparentam ter tido um maior sucesso (+200\%).

No que diz respeito a outras componentes religiosas, não houve oscilaçóes significativas (nem crescimento nem decrescimento) a propósito das religióes de matriz afro- brasileiras $^{9}$ que representam, hoje, acerca do 0,31\% da população (acerca de 590000 pessoas).

A categoria "outras religióes ${ }^{10}$ » teve um crescimento de acerca $2 \%$ nas últimas três décadas, portanto pouco significativo, representando, hoje, acerca do $5 \%$ da população (acerca de 10 milhóes de pessoas).

Por fim, a categoria «sem - religiäo» ${ }^{11}$ que hoje conta com acerca de 15 milhóes de pessoas, registrou um crescimento, passando de 4\%, em 1990 para 8\% no 2010.

Em termos numéricos, portanto, o crescimento evangélico / pentecostal é considerável. Dito diferentemente, na atualidade 1 entre cada 5 brasileiros são evangélicos. Contudo, a religiáo católica continua sendo a religião hegemônica dentre as quais os brasileiros se identificam (Sanchis, 1997; Carvalho, 1999; Pierucci, 2012).

Consideramos, agora, o levantamento realizado durante a pesquisa de doutoramento sobre as religióes dos atletas do Sport Club Internacional de Porto Alegre ${ }^{12}$, pode-

$9 \quad$ No que diz respeito às religióes afro-brasileiras, a sua invisibilidade, em termos numéricos, pode ser interpretada como uma tendência sócio - política dominante que recusa respeitabilidade e até o estatuto de «religião» às religióes afro-brasileiras, fato, isto, que limita a sua liberdade de expressão (Oro, 2012).

Além disso, sabe-se que o universo religioso afro está intimamente «trançado com a experiência do catolicismo» (Sanchis, 1997, p. 31), demonstrando que é muito provável que muitos que se declararam católicos sejam também cultores do universo das religióes afro-brasileiras. $\mathrm{O}$ fato de compartilharem um universo simbólico relativamente homogêneo (Sanchis, 1997 mas também Carvalho, 1999) faz com que as «fronteiras» religiosas "percam muito das sua consistências empíricas» (Montero, 2006, p. 61).

Apesar disso, o que podemos ver, a partir do censos demográficos aqui utilizados, é como "práticas religiosas que compartilham o mesmo código se situam em posições estruturais diversas nessa relação entre Estado, sociedade civil e mundo da vida» (Montero, 2006, p. 58). Nesse sentido, a posiçáo de invisibilidade do universo das religióes afro-brasileiras pode ser lida também como um reflexo de um processo histórico de legitimação e do seu reconhecimento como Religiáo, que, no caso da Umbanda, teve que esperar até os anos 1950-60 (a propósito, ver Montero (2006) e Giumbelli (1998)).

10 A esse respeito, ver Carvalho (1999).

11 De acordo com Rodrigues (2011, in: Oro, 2012, p. 190) a categoria é constituída por «tipos distintos, desde aqueles que rejeitam o transcendente até outros que adotam um modelo de religiosidade particular (geralmente) desinstitucionalizados, que descolam sua religiosidade das instituiçôes religiosas tradicionais».

12 «O Sport Club Internacional, conhecido apenas por Internacional, Inter, SC Internacional ou ainda Inter de Porto Alegre é um clube esportivo brasileiro de futebol da cidade de Porto Alegre, 
-se afirmar, com base nos dados recolhidos em um grupo de 100 atletas das categorias de base $^{13}$, que existe uma porção quantitativamente significativa de evangélicos.

Dos 100 jogadores que responderam à pergunta «religiáo», 56 se declararam católicos, 34 evangélicos, 8 «sem - religiāo», 1 umbanda e 1 espirita.

Cruzando os dados, ou seja, comparando os números da escala nacional, o que se pode ressaltar é um aumento ainda mais consistente dos evangélicos no que diz respeito ao ambiente esportivo ( $34 \%$ contra o $22 \%$ da tendência nacional), um decrescimento dos católicos (56\% contra o $65 \%$ tendência nacional), enquanto «sem religião» (8\%) e "afro» (1\%) apresentam-se sem variaçóes em relação à tendência nacional.

Em relação aos números apresentados, portanto, o crescimento evangélico é ainda mais considerável.

Dito diferentemente, a propósito do futebol, particularmente em relação ao Sport Club Internacional, 1 cada 3 jogadores são evangélicos. Os católicos continuam sendo a maioria, mas, contudo, a sua hegemonia é posta em disputa para o avanço evangélico, neopentecostal em particular.

\section{RELIGIÃO E ESPORTE: MODALIDADE MUSCULARIDADE CRISTÃ}

De um ponto de vista histórico, sabe-se que religiāo e esporte (e vice-versa) estiveram sempre em uma relação tensional, em particular no que diz respeito da contraposição corpo / espírito (Mcloed, 2004; Parker e Watson, 2011; Korsgaard, 2011, Martelli e Porro, 2013).

Nos limitaremos a repercorrer, brevemente, a sua evolução, focalizando a nossa atenção à Inglaterra da era vitoriana (1837-1901), período de transição entre os esportes tradicionais e o surgimento dos esporte modernos (Elias, 1992; Guttmann, 1978; Darbon, 2008).

De acordo com Martelli et al. (2013) na primeira modernidade, o que prevalece é uma desconfiança dos ambientes religiosos em relação aos esportes, isto é, herança de uma ética cristá puritana.

Mcloed (2004) também sinaliza o antagonismo de um protestantismo evangélico puritano, na Inglaterra do começo do século XIX, em relação aos esportes tradicionais e às dife-

no Rio Grande do Sul». Disponível em: <http://www.wikipédia.org/wiki/Sport_Club_Internacional>.

13 Em particular as categorias sub-23 / sub-20 / juvenil A (17/16 anos) e juvenil B (15/14 anos). 
rentes formas de sporting parson ${ }^{14}$ : «les protestants évangéliques de cette époque avaient une vision très restrictive des plaisirs autorisés. Ils admettaient les loisirs comme un mal nécessaire, mais regardaient la majorité des loisirs populaires ou comme immoraux en tant que tels, ou du moins comme menant potentiellement au péché» (Mcloed, 2004, p. 3).

A partir das décadas de 1840 e 1850 é possível reparar uma atitude mais favorável da parte do Clero no que diz respeito aos esportes. Em 1857 (Mcloed, 2004) é cunhado o termo de "muscular Christians»" ${ }^{15}$ que descreve um movimento, de origem anglicana, que combina oficialmente práticas religiosas e atividade esportiva.

Resumidamente, o projeto muscular Christians envolvia considerações teológicas, sociais e políticas.

De um ponto de vista teológico, o movimento contrapunha-se fortemente a uma ética cristã de negação do corpo em relação as questóes espirituais, ou seja, a todas separaçáo sagrado / profano. Os cristáos devem se interessar «a chaque domaine de la vie - les choses physiques aussi bien que les spirituelles; le corps, aussi bien que l'âme, est donné par Dieu et il faut se réjouir des plaisirs physiques» (Mcloed, 2004, p. 5).

Parker et al. (2011, p. 82) ressaltam também a importância do papel da igreja anglicana, a partir da segunda metade do século XIX, em «desenraizar o forte senso de puritanismo que permeava os seus ambientes».

Politicamente, o discurso da muscularidade cristã, ou seja a reavaliação dos esportes e do loisir no ambiente religioso, tinha o objetivo de reaproximar a classe operaria e os teenagers à Igreja, reconhecendo nos esportes um potente "agente de socialização» (Parker et al., 2011, p. 84).

A esse respeito, não custa lembrar a influência que a muscular Christianity exercia nas public schools assim como nas paroisses ouvrières. (Mcloed, 2004).

De acordo com Mcloed (2004, p. 7):

«Le clergé sportif de cette époque était très souvent animé par deux préoccupations: la conversion des ouvriers et, surtout, la conversion des jeunes hommes. (...) L'un des pionniers de ce mouvement fut un prêtre évangélique, le révérend J.C. Miller (...) en 1854 fonda une association (...) le cricket et le football faisaient partie de son programme (...) au même titre que l'étude de la Bible.

14 De acordo com Mcloed (2004, p. 3): «le sporting parson (prêtre amateur de sport) était un personnage familier, surtout en milieu rural, qui encourageait les activités sportives de ses paroissiens tout en pratiquant activement lui - même. Les sporting parson participait à la chasse (...) mais aussi au sport plus plébéien du combat de coq".

15 Segundo Parker et al. (2011, p. 80) o termo de "muscular Christianity» sintetiza "pureza espiritual, moral e física com uma particular concepção da virilidade cristã». 
Dans les public schools (...) le directeur d'une public school était toujours un membre du clergé anglican, et la religion jouait un grand rôle dans ses écoles (...) l'influence de l'anglicanisme libéral était particulièrement grande. (...) Les public schools devinrent des terres d'élection pour la muscular Christianity».

Se parte da Igreja Anglicana, denominada de serious Christians, mantinha uma política de negação em relação aos esportes tradicionais e do loisir, a Muscular Christianity era responsável, ao contrário, por um empreendimento que fazia do conúbio religião / esporte o seu "cavallo di battaglia».

Sintetizando: a «muscular Christianity (...) voulait regagner les jeunes et les ouvriers à l'Église. Et, pensait-on, le sport pouvait prendre part à cette entreprise» (Mcloed, 2004, p. 7).

\section{OS ATLETAS DE CRISTO: MUSCULARIDADE CRISTÃ PÓS-MODERNA}

A nossa intenção, aqui, é de avançar algumas comparaçóes preliminares entre o movimento da muscularidade cristã que teve a sua máxima expansão por volta da década de 1890 / 1930 (Mcloed, 2004) e o grupo neopentecostal denominado Atletas de Cristo ${ }^{16}$, que surgiu no Brasil na década de 1980, graças a um então atleta do Clube Atlético Mineiro, João Leite (Aguiar, 2011).

De acordo com Aguiar (2011, p. 231) «apenas em 1981, com a criação de um grupo de apoio formado com gente suficiente para suportar o nascimento de uma instituição, é que o nome "Atletas de Cristo", sugerido por Eliana Aleixo, na época estrela do vôlei brasileiro e esposa de João Leite, passa a denominá-los».

Passaram-se trinta e quatro anos desde que os Atletas de Cristo nasceram, e seu crescimento numérico ${ }^{17}$, também além das fronteiras nacionais com o surgimento de ministérios no exterior ${ }^{18}$, testemunha o seu sucesso.

Embora o movimento dos Atletas De Cristo não se posicione formalmente em relação às diferenças doutrinárias e aos pontos polêmicos existentes no campo evangélico,

16 Sobre esse assunto ver Jungblut (1994) e Aguiar (2011). As informaçóes sobre o surgimento desse grupo podem ser também obtidas na página oficial de ADC na Internet (<http://www.atletasdecristo.com.br>).

17 De acordo com Aguiar (2011, p. 232) «Hoje ADC conta com mais de seis mil atletas brasileiros, atuando no Brasil e em dezenas de países (Argentina, EUA, Portugal, Espanha, França, Itália, Turquia, Japão, etc.)».

18 Na Itália, por exemplo, os Atletas de Cristo surgiram na década de 1998 com os então jogadores de futebol, Paulo Sergio (Roma), Paulo Pereira (Genoa), ambos brasileiros (in: <http://www.atletidicristo.org>). 
é fácil relacioná-lo com a componente evangélica neopentecostal que surgiu também na década de 1980.

De fato, da pesquisa de doutoramento pudemos avançar que o futebol está se tornando cada vez mais «evangélico».

\section{Como explicar esse nexo futebol-neopentecostalismo?}

Como se difundiu entre atletas desse esporte?

Haveria uma relação entre a política da muscularidade crista e o grupo dos Atletas de Cristo?

Segundo Rial (2013, p. 3) a presença do neopentecostalismo no futebol coincidiria com «o aumento meteórico das igrejas evangélicas no Brasil».

Isto significa que haveria uma correlação entre o avanço evangélico (+ 200\% em três décadas a nível nacional) e a presença do neopentecostalismo no futebol.

Os dados que analisamos a propósito do pertencimento religioso nas categorias de base do Sport Club Internacional evidenciaram um crescimento evangélico superior em termos numérico (34\% contra o $22 \%$ da tendência nacional) no ambiente futebolístico.

A partir disso podemos deduzir que o futebol é um campo bem mais sensivel e receptivo à "chamada evangélica».

Sim, mas porque próprio o neopentecostalismo?

A respeito disso, Rial (2013) sublinha também uma correlação entre as camadas sociais da baixa classe média, que aderiram ao neopentecostalismo, e os atletas desse esporte.

Da pesquisa de doutoramento é possível acrescentar alguns dados que corroboram essa tese.

Se tomarmos como indicador o grau de escolaridade das famílias dos 100 atletas do Sport Club Internacional, 15 declararam possuir o nivel superior completo. O restante 85\% declarou possuir um nivel de escolaridade que varia entre o Ensino Fundamental e Médio completos ou incompletos. Isto corroboraria a tese segundo a qual haveria uma correlação entre as camadas da baixa classe média e as famílias dos atletas desse esporte.

Avançando na nossa análise, é possível ressaltar que, das 15 famílias com nivel superior de escolaridade, 13 declararam se católicas enquanto 2 evangélicas. Ou seja, o $86 \%$ de quem possui um grau de escolaridade superior é católico. 
Portanto, os dados, corroborariam a tese que o neopentecostalismo é uma religião que mais se adapta as camadas sociais da baixa classe média ${ }^{19}$ (Sanchis, 1997) que sonham enriquecerem por meio do profissionalismo esportivo, futebolístico em particular ${ }^{20}$.

Sabe-se também que o futebol é um ambiente cercado de «situaçôes intangiveis» (uma bola na trave, um pênalti desperdiçado, uma lesão $e t c . .$.$) e que a recorrência a prá-$ ticas mágicos / religiosas é comum para "controlar o incontrolável», ou seja situações que escapam de uma lógica racional.

De acordo com Jungblut (1994, p. 116):

«O meio futebolístico brasileiro sempre foi um território coberto por uma nevoa de religiosidade e magia. Uma arena como esta (...) não poderia deixar de ser um lugar onde todos os meios naturais e sobrenaturais são usados para atingir objetivos: vitórias, sucessos, imortalidade, dinheiro».

Ademais, em particular no que diz respeito às categorias de base, não devemos desconsiderar a condição de seres liminare ${ }^{21}$ que faz que os atletas mais jovens sejam os mais vulneráveis e sensiveis a um discurso sedutor religioso que anuncia sucesso e dinheiro imediato além de uma forte fundação de ajuda e solidariedade. (Rial, 2013; Jungblut, 1994).

Nesse sentido, o neopentecostalismo, muito mais do catolicismo (Rial, 2013) consegue, hoje, produzir um discurso performático, ou seja, um discurso capaz de produzir sentido.

Dito diferentemente, o neopentecostalismo é performático próprio porque é capaz de dar «sentido» ao mundo dos jogadores de futebol, sejam eles jovens atletas ou consagrados campeóes ${ }^{22}$.

19 De acordo com Sanchis (1997, p. 30) se sabe que a «explosão» pentecostal atingiu, desde o início, «as camadas populares (....) hoje ainda, apesar de uma nítida presença em outras camadas e de certa ascensão social dos grupos pentecostais primitivos, o espectro pentecostal, se corresponde ao perfil geral brasileiro quanto à população de renda média baixa».

20 A título de exemplo, e muito superficialmente, é possível ressaltar que a maioria dos atletas das categorias de base do Sport Club Internacional que responderam à pergunta «o que te motiva a continuar num esporte que te exige tanto esforço?» declararam que o objetivo principal é de «ajudar a família economicamente».

21 Entendo com seres liminares aqueles que estão expostos a situação de contínua tensão e risco, entre vida e morte simbólica, ou seja, no caso dos jogadores, estão entre serem dispensados ou mantidos no clube, processo que permeia a formação dos atletas. Próprio por esta razão, Jungblut (1994) pôs em evidência o nexo entre a fragilidade desta situaçáo, sempre em risco de escassez, e o recurso ao universo simbólico próprio do mundo mágico / religiosos para matizá-la. A condição de seres liminares, ou seja de quem não possui nada (Turner, 1974) os obriga a procurar incessantemente uma posição, um status, que porém é aleatório: a cada jogo é preciso reforçar o que se conquistou no jogo anterior (por exemplo, uma posiçáo estável no plantel «dos onze eleito»).

22 Kaká, talvez, possa ser considerado na atualidade o representante mais famoso mundialmente entre os Atletas de Cristo no mundo. 
De acordo com Rial (2013, p. 6):

"O neopentecostalismo oferece uma cosmologia capaz de integrar as novas experiências de vida destes jogadores (experiência de viver no exterior, em solidáo) assim como possibilita, para os jogadores - celebridades, viver como milionários sem culpa. Ao contrário do catolicismo que prega a simplicidade e concentra-se na vida após a morte, o neopentecostalismo faz das riquezas materiais um bom diálogo com Deus»

Assim como os seus ancestrais evangélicos britânicos libertários da muscularidade cristã, que romperam com uma tradição puritana de negação dos esporte, os neopentecostais, e, no que diz respeito do esporte, o grupo denominado Atletas de Cristo, a muscularidade cristã pós-moderna, também romperam com uma tradição evangélica "forte» que, como diz Rial (2013) associava "a bola de futebol (e de outros esportes) ao ovo do Diabo", ressignificando e ressimbolizando as práticas esportivas dentro de uma visáo cristá libertaria (em particular a partir da teologia da libertação, da década de 1970, das igrejas pentecostais e da teologia da prosperidade [Rial, 2013]).

O grupo dos Atletas de Cristo, hoje, assim como a muscularidade crista da década de 1890/1930, tem como objetivo recombinar práticas religiosas e atividades esportivas ${ }^{23}$.

Ou seja, ontem como hoje, o esporte se configura como um território de (re) conquista cristâ, de renegociação de fiéis, em suma, um «canal por onde passa a palavra de Deus»(in: atletatsdecristo.org).

No site atletasdecristo.org está resumido o objetivo dos Atletas de Cristo:

«Hoje o esporte é de fundamental importância no mundo e consequentemente no Brasil, são milhares de praticantes em nosso país (...) atletas surgindo a todo momento. Somos o país do futebol, do vôlei, da ginástica, da nataçấo entre tantos outros, prova de que o esporte tem alcançado outros adeptos com habilidades distintas além do querido futebol, este por sua vez temos que ressaltar: é o esporte com mais ênfase no Brasil e que abre grandes portas no mundo inteiro. Entendemos tudo isto de maneira benéfica e por que não dizer oportuna para a pregação do evangelho da salvação, temos intensificado nossos esforços, nossas açōes, e nossos melhores dias para tornar o esporte um grande canal por onde passa a Palavra de Deus e alcança os coraçóes dos mais apaixonados e praticantes esportivos do Brasil e do mundo. (...) Seja um Atleta de Cristo.»

23 Parker et al. (2011, p. 84) reconhecem que houve nos Estados Unidos da América, a partir da segunda metade do século $\mathrm{xx}$, movimentos evangélicos protestantes que demonstraram «muita atenção em replicar a aproximação dos primeiros "Muscular Christians» através a fundação de organizaçôes esportivas evangélicas (Athletes in Action e o Fellowship of Christian Athletes)». 
Nessas quatros linhas reencontramos, portanto, o espirito da muscularidade cristã de origem britânica de fazer do esporte palco de pregação e de conquista.

\section{CONSIDERAÇÕES FINAIS}

Por que o neopentecostalismo é tão atento ao mundo do esporte, e do futebol,em particular?

Hoje, a (hiper)visibilidade que os esportes, o futebol em particular, alcançaram é infinitamente maior que o futebol do começo do século xx, graças aos meios de comunicação e à rapidez com a qual as imagens se difundem na sociedade pós-moderna (Balandier, 2004; Augé, 1996; Bobineau, 2011).

Isto faz com que, hoje, muito mais que ontem, os esportes se tornem espaços globais / transnacionais extremamente interessantes de propaganda religiosa (Rial, 2013).

Nesse contexto, os Atletas de Cristo, portanto, se configuram como a muscularidade crista da sociedade pós - moderna, ou seja, como «embaixadores» ou «soldados da fé» (Rial, 2013, p. 8) em busca de novos fiéis em escala global/transnacional.

A titulo de exemplo, Clemer ${ }^{24}$, Atleta de Cristo, declarou a imprensa:

«Eu sou um filho de Deus, um pregador da palavra de Deus, dou o meu testemunho... é claro, Deus me usa hoje praticamente como uma isca para ganhar pessoas, devido aos títulos que eu ganhei, por tudo que passei na minha carreira, as pessoas vão lá para ver o Clemer e acabam aceitando Jesus e seguindo o evangelho de Deus».

O seu testemunho sintetiza o empreendimento neopentecostal a partir dos seus Atletas de Cristo. Não custa lembrar que, assim como hoje, os Atletas de Cristo são esportivos religiosos, também os integrantes da muscularidade cristã praticavam esportes (Mcloed, 2004).

Se, como sustenta Rial (2013, p. 7), os Atletas de Cristo, "promovem crenças religiosas em escala global», através gestos simbólicos quais «levantar suas mãos ao céu para celebrar um gol, ajoelhar-se após fazer um gol, proferir alguma benção (...) inscriçôes de

24 Numa entrevista realizada no dia 01 de novembro de 2011 (disponível no YouTube em <https:// www.youtube.com/watch? $v=$ dgmZoTXQXcM>) Clemer, ex goleiro do Sport Club Internacional, testemunha a sua adesão à fé evangélica sendo "pregador da palavra de Deus» e "seu filho". Da mesma forma, uma análise antropológica do testemunho que o jogador de futebol brasileiro Zé Roberto (hoje Palmeiras) proferiu em ocasião de um evento evangélico organizado pela ADHONEP (associação dos Homens de Negócio do Evangelho Pleno) em Porto Alegre (Brasil) encontra-se em Petrognani (2014). 
palavras sagradas nas suas camisas como Deus é Fiel25, Eu pertenço a Jesus (entre outras), agradecimento a Jesus nas entrevistas (...)» os estádios, nesse sentido, se tornam espaços públicos globais de pregação de grande visibilidade, nos quais o que está em jogo, não é simplesmente a vitoria ou a derrota esportiva, mas, também religiosa.

Portanto, é sobre as relaçôes entre religiâo, futebol e espaço público que se disputa muito dos novos equilíbrios no que diz a respeito do campo religioso brasileiro

Por fim, como tentamos avançar ao longo do nosso ensaio sobre o futebol, os neopentecostais, muito mais que "umas das religióes periféricas» (Carvalho, 1999, p. 3), estão se tornando no ambiente futebolístico de formação profissional, cada vez mais, uma religião "hegemônica» quase quanto o catolicismo.

Quem ganhará esta "partida»?26

\section{REFERÊNCIAS BIBLIOGRÁFICAS}

Aguiar, R. O. (2011). Deus é mais: a supremacia da fé evangélica na ótica dos Atletas de Cristo. Revista Brasileira de História das Religióes, Ano III, N 9 , pp. 229-252.

Augé, M. (1996). Le sport comme phénomène surmoderne. Recherche en communication, $\mathrm{N}^{\circ}$ 5, pp. 159-173.

Balandier, G. (2004). Ce que disent le corps et le sport. Corps e Culture, N 6/7, pp. 1-4.

25 Giumbelli (2004, p. 47) concorda em associar expressóes tais como «Deus é fiel «com indícios de religiosidade pública - algo que se associa a expansão dos evangélicos nas ultimas duas décadas no Brasil e ao seu impacto social e político».

26 Como recordam Martelli et al. (2014, p. 80) a FIFA reagiu às manifestaçóes públicas de religiosidade que os jogadores da seleçáo brasileira manifestaram depois da conquista da Copa das Confederaçóes em 2009 através da exposição de camisas, bandeiras de agradecimento a Deus, assim como o fechamento à brasileira, ou seja a típica corrente/roda que os jogadores brasileiros estáo acostumados a realizar antes e depois dos jogos, e que se caracteriza pela reza do Pai Nosso, além de posturas e gestos, tais como se ajoelhar, levantar as suas mãos ao céu, que são associadas a uma religiosidade de marca evangélica, dando disposiçóes para prevenir ulteriores expressóes de religiosidade durante os Mundiais. De fato, a FIFA (como a UEFA), em proibir manifestaçóes públicas de religiosidade nos estádios durante as competiçôes internacionais, posiciona-se, voluntariamente ou não, a propósito da problemática entre religião e espaço público, de forma radical, ou seja, adotando uma idéia de laicidade que resulta na neutralização e homogeneização do espaço público, colocando a religião na esfera do privado. Apesar da CBF (o código brasileiro de Justiça Esportiva) também proibirem qualquer manifestação religiosa dentro dos estádios, portanto adotando também uma postura de exclusão da religião nos seus espaços públicos, ou seja adotando uma política à européia, as mesmas continuam sendo praticadas, em particular através seus Atletas de Cristo, como foi o caso, por exemplo, da polêmica envolvendo o goleiro Jefferson (Botafogo) que atuou, no 2013, com o desenho de um peixe no corte de cabelo, símbolo cristão. (In: <http:// www.sportv.globo.com/atletas-de-cristo-jefferson>). 
Brba, B. (2007). Un antropologo nel pallone. Roma: Meltemi Editore.

Baubérot, J. (2011). Libertà religiosa e laicità in Francia. Lessico di etica pubblica, $\mathrm{N}^{\circ}$ 2, pp. 59-70.

Bobineau, O. (2011). La troisième modernité, ou «'individualisme confinitaire». SociologieS, Théories et recherches, <http://sociologies.revues.org/3536>.

Bromberger, C. (1995). Le match de football: ethnologie d'une passion partisane à Marseille, Naples et Turin. Paris: Editions de la Maison des sciences de l'homme.

Carvalho, J. J. (1999). Um espaço público encantado. Pluralidade Religiosa e Modernidade no Brasil. Série Antropologia, UNB, N²49, pp. 1-22.

Casanova, J. (2013). As religiôes estão se tornando cada vez mais globais. Revista Instituto Humanitas Unisinos, 2013. Recuperado em: 2 dez. 2013. <http:// www.ihu.unisinos.br>.

Cipriani, R. (1981) Sécularisation ou retour du sacré ? Arch. Sc. Sociologie des religions, $\mathrm{N}^{\circ}$ 52/2, pp. 141-150.

Cipriani, R. (1983) Religione e politica. Il caso italiano: la religione diffusa. Studi di Sociologia, Roma.

Cipriani, R. (2011). Dallo spirito allo sport e viceversa. Il gioco della vita quotidiana quando la vita è in gioco. Religione e Società-Rivista di scienze sociali della religione, Anno XXVI, Pisa-Roma, pp. 61-69.

Darbon, S. (2008). Diffusion des sport et impérialisme anglo-saxon. De l'histoire événementielle à l'anthropologie. Paris : Édition de la Maison des Sciences de l'Homme.

Elias, N. (1992). Ensaio sobre o desporto e a violência (Elias, n. e Dunning, E.). A Busca da Excitação, Lisboa: Difel.

Freston, P. (1994). Breve história do pentecostalismo brasileiro. Nem anjos nem demônios: interpretaçôes sociológicas do pentecostalismo, Vozes, pp. 67-162.

Gauchet, M. (1985). Le Désenchantement du monde. Une histoire politique de la religion. Paris: Gallimard.

Geertz, C. (2001). O beliscão do destino: a religião como experiência, sentido, identidade e poder. Nova luz sobre a Antropologia, Rio de Janeiro, Jorge Zahar, pp. 149-165. 
Giumbelli, E. (2004). Religião, Estado, modernidade: notas a propósitos de fatos provisórios. Estudos Avançados, 18(52), pp. 47-62.

Guttman, A. (1978). From Ritual to Record: the Nature of Modern Sports. New York: Columbia University Press.

Jungblut, A. L. (1994). Entre o Evangelho e o Futebol: um estudo sobre a identidade religiosa de um grupo de Atletas de Cristo em Porto Alegre. Dissertação de Mestrado em Antropologia Social, UFRGS, Porto Alegre.

Korsgaard, O. (2011). Lo sport come rito della modernità. Religione e società Rivista di scienze sociali della religione, Anno XXVI, Pisa-Roma, pp. 70-78.

Luckmann, T. (1967). La religione invisibile. Bologna: Il Mulino.

Mariano, R. (1995). Neopentecostalismo: os pentecostais estão mudando. Dissertação de mestrado, USP, São Paulo.

Mariano, R. (2011). Laicidade à brasileira: católicos, pentecostais e laicos em disputa na esfera pública. Civitas, Porto Alegre, pp. 238-258.

Martelli, S. \& Porro, N. (2013). Manuale di Sociologia dello Sport. Milano: FrancoAngeli.

McLoed, H. (2004). La religion et l'essor du sport en Grande-Bretagne. Revue d'histoire du XIX siècle, pp. 2-15. DOI: 10.400/rh19.624.

Montero, P. (2006). Religião, pluralismo e esfera pública no Brasil . Novos Estudos Cebrap, pp. 47-65.

Monterom P. (2009). Secularizaçấo e espaço público: a reinvenção do pluralismo religioso no Brasil Etnográfica,vol. 13(01), pp. 7-16. DOI: 10.400/etnográfica.1195.

Oro, A. P. (2000). O feiticeiro recorre ao judiciário: Os limites do multiculturalismo. Revista USP, São Paulo, N46, pp. 129-138.

Oro, A. P. (2003). Neopentecostalsimo:dinheiro e magia. Anuario Antropologia Social y Cultura en Uruguay 2002-2003, Montevideo, pp. 205-214.

Oro, A. P. (2005-2006). O neopentecostalismo macumbeiro. Revista USP, São Paulo, No68, pp. 319-322.

Oro, A. P. (2010). Reciben lo que veniran a buscar - nação e poder num encontro evangélico internacional, em Buenos Aires. Religiáo e Sociedade, Rio de Janeiro, 30(1), pp. 32-52. 
Oro, A. P. (2011). A laicidade no Brasil e no Ocidente: algumas considerações. Civitas, 11(2) Porto Alegre, pp. 221-237.

Oro, A. P. (2012). Liberdade religiosa no Brasil: as percepçóes dos atores sociais. A religiāo no espaço público. Antropologia hoje, São Paulo, Terceiro nome.

Parker A. \& Watson, N.J. (2011). Sport, spiritualità e religione: «Muscular Christianity» e oltre. Religione e società - Rivista di scienze sociali della religione, Anno XXVI, Pisa-Roma, pp. 61-69.

Petrognani, C. (2014). Estou aqui como um profeta de Deus: Zé Roberto, o futebol e a religiosidade como beliscáo do destino. Debates do Ner, 15(26), pp. 229-252.

Pierucci, F. (2012). O crescimento da liberdade religiosa e o declínio da religiáo tradicional: a propósito do censo 2010. Anuac, 1(2), pp. 87-96. DOI: 10.7340/anuac2239-625X-36.

Piette, A. (1993). Les religiosités séculières. Paris: PUF.

Rial, C. (2008). Rodar: a circulação dos jogadores de futebol brasileiros no exterior. Horizontes Antropológicos, 14(30), pp. 21-65.

Rial, C. (2012). Banal Religiosity: Brazilian Athletes as New Missionaries if the Neo-Pentecostal Diaspora. Vibrant, 9(2), Brasilia, pp. 130-159.

Rial, C. (2013). «O ovo do diabo» e os jogadores de futebol como pastores neo-pentecostais. Revista Instituto Humanitas, $\mathrm{n}^{\circ}$ 424. Recuperado em: 2 dez. 2013. <http://www.ihu.unisinos.br>.

Sanchis, P. (1997). As religiōes dos brasileiros. Horizonte, Belo Horizonte, 1(2), pp. 28-43.

Weber, M. (2003). L'Éthique protestante et lesprit du capitalisme. Paris: Gallimard. 
Página intencionadamente en blanco 